\title{
USER SATISFACTION THROUGH TIME, COST AND VISIT (TCV) MODEL: CASE OF MAYOR MOHAMMAD HANIF FLYOVER
}

\author{
Abu Hossain Muhammad Ahsan ${ }^{1}$ \\ Elora Sharmin Ela ${ }^{2}$ \\ Azizur Rahman ${ }^{3}$ \\ Riffat Farhana ${ }^{4}$
}

\begin{abstract}
Governments around the world are encouraging private individuals, groups or organizations to join hand in hand in delivering better services to the citizens. Similarly, Government of Bangladesh has also initiated Public Private Partnerships (PPP) in its policies and strategies over the years. Mayor Muhammad Hanif Flyover (MMHF) is one of the key examples of large-scale project implemented under PPP in the country. The main objective of this paper is to assess the level of satisfaction of the service users of MMHF and associated factors that either facilitate or hamper user satisfaction. This study follows a mixed research method with both quantitative and qualitative data collection techniques; small scale survey and interview applied to cover primary sources and content analysis has been applied to get information from secondary sources. This study customizes TCV (time, cost and visit) model used by a2i to assess the efficacy of the use of MMHF. This study finds that most of the service users are satisfied with the time needed to pass through the flyover against the costs incurred and thereby they happily avail the flyover. Despite some challenges this PPP project has paved the opportunity to introduce more partnerships between government and the private sector.
\end{abstract}

Keywords: user satisfaction; Public Private Partnerships; Mayor Mohammad Hanif Flyover; TCV model; UDC

1 Abu Hossain Muhammad Ahsan, is Associate Professor, Department of Public Administration, University of Dhaka. Email: abuhmahsan@du.ac.bd

2 Elora Sharmin Ela is Assistant Professor, Department of Development Studies, University of Dhaka.Email: eladu2005@yahoo.com

3 Azizur Rahman, is Assistant Professor, Department of Public Administration and Governance Studies, Jatiya Kabi Kazi Nazrul Islam University. Email: abir7du@yahoo.com

4 Riffat Farhana, is Assistant Professor, Department of Public Administration, Jagannath University. Email: riffat.farjanajnu@gmail.com

Social Science Review [The Dhaka University Studies, Part-D], Vol. 37, No. 2, December 2020 


\section{Introduction}

Public Private Partnership (PPP) is now a very widely used and accepted model of development around the world, which is made on mutual trust, respect, sacrifice as well as mutual dependence. It is the latest innovation in development discourse and is a dominant paradigm that has emerged in so many regions to develop large scale infrastructure. It is also used for promoting competitiveness, effectiveness, maintenance, and sustainability of various projects. Since independence in 1971, the development administration has been experiencing challenges and drawbacks; administrative, planning, financial, etc. The country requires large scale investment in energy, water supply, infrastructure, transport and several other sectors with a view to meeting these challenges. Improvement and investments in these sectors would create employment, improve scope of income generation and facilitate industrialization and improved communication. In mid-2009, encouraging of public private collaboration was included in the position paper of PPP by the Finance Division of the government of Bangladesh in the budgetary legislation. The concept of PPP is an important aspect of donor driven country development thoughts and a central component of foreign policy towards development countries (Islam \& Mehjabeen, 2011). The GoB first introduced the concept of PPP in its FY 2009-2010 national budgets and made a significant allocation of funds for PPP projects, demonstrating a strong commitment from the GoB to the implementation of PPPs in the country. The government also issued a position paper on PPP entitled, 'Invigorating Investments Initiative through Public Private Partnerships", in June 2009 (http://www.projectsprofile.com/info/financial_one.html). Despite all these commitments, the PPP initiative did not achieve significant results in terms of implementation of the PPP projects. This was mainly due to the absence of clear policy and strategic guidelines. To fill this gap, the GoB issued the "Policy and Strategy for Public Private Partnership (PPP), 2010" in August 2010 (Government of Bangladesh, 2010). Government has so far taken important projects under PPP which include different sectors like infrastructure, transport, power, and energy. An effective and efficient planning and implementation of these projects would bring about significant changes in the development paradigm of the country and the citizens of the country would experience better and quality services rendered by service providing agencies.

One of the major drawbacks of development, especially in the field of communication, is the world's worst traffic congestion in the capital city, Dhaka. 
The impact of travel time cost and travel delay externality cost, vehicle operating cost and excess fuel cost occurred due to traffic congestion in Dhaka city are quite significant (Chakraborty, 2016). For making smooth and relatively accessible traffic network with and within the Dhaka City area, Bangladesh Government planned to construct a Flyover between Gulistan and Jatrabari connecting the Dhaka-Chattogram Highway. The road was well known for its' high traffic congestion for a long period of time. After so many pauses inbetween, the construction of Mayor Mohammad Hanif Flyover finally completed and made open for public use in 2013. The main flyover is connected with 6 entry ramps and 5 exit ramps to facilitate inbound and outbound movement of the crossroad traffic in the flyover location. The total length of the elevated corridor is $10.6 \mathrm{Km}$ of which approximately $4.1 \mathrm{Km}$ is main flyover having 4-lane divided carriageway and approximately $6.1 \mathrm{Km}$ is ramps having 2-lane carriageway. Dhaka City Corporation was authorized by Local Government Engineering Department (LGED) of GoB to implement this huge project based on Build-OwnOperate-Transfer (BOOT) method with the private sectors. The contract was awarded to a leading company through competitive bidding, who are the Concessionaire of the project. (www.mmhf.com). One of the landmark steps of infrastructural development in Bangladesh is the implementation of Mayor Muhammad Hanif Flyover (MMHF). It is situated in the main entry point of the capital city. However, although it is a very vital project and has the great opportunity in promoting economic development through easing communication of around 30 districts with and to the capital city. The implementation of this mega project had to face so many barriers; financial, political, technological, etc. Even after the implementation, this project still faces several negative impacts or feedbacks. It has been reported in newspapers and by individual users that the amount of Toll service users has to pay is one of the major constrains in the smooth operation of the project. This study has been undertaken to find out if the users are satisfied with the overall impacts of the project, especially in terms of TCV (Time, Cost and Visit) measurement and thus to suggest some strategies to make the project as well as PPP fruitful and user friendly.

\section{Objectives of the Study}

The foremost objective of this paper is to assess whether the service users are satisfied with the service provided by the agencies, such as average time required to pass through the flyover, with the cost of rendering service. This study will 
also explain whether the satisfaction in terms of time and cost reflects the increased number of uses of the flyover. And whilst, the issues and problems with the service providing agencies will also be studied to cross match the demand and supply side of the project. The study team will also try to suggest remedies of the problems.

\section{Literature Review}

User satisfaction or citizen's satisfaction, what might be the term, has been a widely used variable to measure the level of satisfaction for public and private goods and services. The intention of satisfaction survey is to hear from the citizens or users about the services being studied (Van Ryzin, Muzzio, Immerwahr, Gulick, \& Martinez, 2004) The techniques that are applied to measure the level of satisfaction also varies from country to country, region to region and even sector to sector. In Bangladesh, Access to Information (a2i) unit of the Government of the People's Republic of Bangladesh (GoB) introduced TCV (time, cost, and visit) model especially in the field of measuring services provided through digital or e-Governance where they argue that reducing time, cost and visits in rendering services eventually increases the level satisfaction of the service users.

Islam, Anwari and Hoque (2018) conducted a research on MMHF to investigate whether the objectives of this mega project have been met. They developed some performance indicators to measure the objectives against those. They applied methodological survey incorporating temporal variation to investigate the flow of vehicular transportation. Based on temporal observation method through CCTVs they explained the number of vehicles passes through the flyover and they showed the variation of use of flyover in case of weekdays, weekends, day, and night. The study also found that this project does not provide any facility for non-motorized vehicles and some of the users are not satisfied with the service cost (rate of the toll). The same team of authors conducted another study on MMHF to explore if this project became successful in reducing rail-road traffic and accidents caused at these junctions. They studied from engineering point of view rather than from the perspective of users' views on satisfaction. Most of the studies conducted by the research group or newspapers on MMHF mainly highlighted on whether the longest flyover of the city could reduce traffic congestion. 
Digitizing administration in Bangladesh is the priority of the current government both in policy issues and their executions of all governmental actions. To achieve this vision, the government has already introduced extensive programmes and projects to reduce TCV in public service delivery and to help it grow and compete with the private sectors. TCV has become one of the most important performance indicators of the government under this vision (Korean International Cooperation Agency, 2018). A2i has so far innovated as many as 2000 apps to ensure better service delivery provided through government agencies and they have been using TCV to measure the level of satisfaction of the service users for long. A2i in collaboration with different research agencies conducts efficiency and impact analysis of these apps through TCV method. Hence, TCV has been an extensively used performance measurement technique in Bangladesh; some of them have been carried out through Public Private Partnership (PPP) model and others are executed through government, autonomous, semi-autonomous agencies, and private sectors.

Since 2006, the Access to Information (a2i) Programme has been significantly transforming public service delivery at minimal time, cost, and visits (TCV) from different government offices. This transformation emphasizing on TCV ensures low-cost public service delivery and thus increases service recipients' satisfaction (Hussain \& May, 2014, p.9-10). The Union Digital Centres (UDCs), a service model developed on PPP principles, has been one of the most successful projects ever implemented to provide service to the people's doorsteps (Access to Information Programme [a2i], 2016). Access to Information (a2i) Programme of the Prime Minister's Office of Bangladesh in collaboration with the Department of Anthropology, University of Dhaka conducted a joint research to evaluate the Union Digital Centres (UDCs) in Bangladesh based on TCV. This study outlines that before the establishment of these UDCs, people had to travel kilometres and stand in long queues to get access to public services and information. Evidence suggests that these UDCs reduced the amount of time, money, and other hassles to get public services as Union Parishads are at their near proximity. The study found that the introduction of UDCs significantly reduce time, cost, and visits (TCV) to render services in most Union Parishads (Rashid \& Hasan, 2018).

The a2i unit of the Prime Minister's Office also conducted a research applying Time-Cost-Visit (TCV) model to study the online application system of the University of Dhaka. The main purpose of the study was to analyse the TCV of 
the applicants who took part in the admission procedure of the University of Dhaka. TCV analysis of this research focused on the effectiveness of a system in online application in a leading public university where thousands of students apply online for the admission tests every year (a2i, 2015). TCV analysis of the online application system of the University of Dhaka reveals that manual application procedure was time consuming, costly, and required unnecessary multiple visits at the concerned offices. But the new online system of the application makes the procedure easy and quick. The candidates are satisfied with the online application system as it needs less TCV and is accessible from anywhere, at any time (Shumi, Saha, Aziz, Elma, \& Ara, 2015).

As stated earlier, there have been quite a few studies conducted on TCV in Bangladesh and insignificantly a few on MMHF. It has been studied that the use of TCV has been carried out only on the services that are carried out online, but it has been proved to be a well-accepted model of measuring citizens' satisfaction on service delivery. On the other hand, despite being the longest flyover and the first one in the Dhaka city that imposed toll to use it, failed to attract the attention of the social researchers who would measure the level of satisfaction of the service users. The research team is privileged to take this opportunity to combine these two; MMHF with TCV model and would customize the variables of TCV models in consistent with the features of offline services. This is a unique attempt to study the models of online measurement in the offline context.

\section{Methodology of the Study}

Mixed method of social research has been applied where both qualitative and quantitative data collection techniques have been used to collect relevant data. Required information and data have been collected both from primary and secondary sources of information. Primarily, the researchers have conducted a small-scale quantitative survey on 100 service users; Truck drivers, CNG drivers, Bus Drivers, Private Car Drivers, and their owners, where applicable. The team, initially, prepared a listing of the service users and then applied random sampling to select these five categories of respondents from the list. Here, it is to be noted that only those drivers who used this service (Flyover) were purposefully sampled under this study. In the first phase of data collection, the research team collected data from 100 respondents on user satisfaction. Subsequently, the result collected from the quantitative survey was triangulated 
through in-depth interviews (IDI). 15 respondents incorporating both service providers and users were rigorously interviewed to instigate the real picture of the research problems. As a means of secondary sources, the reports produced by several agencies, academic journals, Acts and Laws, project documents, etc. were also studied.

\section{Analytical Framework}

Assessment of citizens' satisfaction is an issue exercised by the government of most of the countries in the world to see whether citizens use/buy the public good or services or are satisfied with the quality of services. Citizens' satisfaction measurement/index has been widely used throughout the globe and some of the techniques that have been used in many countries can be mentioned here; Likert Scale, Canada's Common Measurement Tools, Italy and France's Quality Barometer, Satisfaction Barometer in the Scandinavian countries, etc. (Organisation for Economic Co-operation and Development [OECD], 2013). It has been observed that there is barely any uniform measurement scale that is followed by most of the countries, the countries on the contrary customizes the measurement scales on their own, applicable for their own cause. In Bangladesh $\mathrm{a} 2 \mathrm{i}$, as stated earlier, has been doing this for quite a few years, measuring the satisfaction level of the service users on different public goods and services, especially services rendered from the local government units. In most cases, a $2 \mathrm{i}$ used the TCV method to measure the satisfaction level of the citizens where TCV stands for Time, Cost and Visit. The less time, cost and visits needed to receive services refers to better service delivery by the supply end and higher satisfaction level at the demand side.

Under this study, the team customized the TCV model of measuring citizens' satisfaction where TCV would be customized as follows:

Time: To be referred as less time required; in the present context it has been studied whether the service users are satisfied with the amount of time needed to pass through the flyover and it significantly reduces the time than using the surface road.

Cost: Whether the users are satisfied with the cost; in case of using flyover, users have to pay toll but using surface road does not require any service cost. It has been studied if the users are satisfied with the cost they have to spend while passing through it. The assumption is, if using flyover reduces time, people are 
even satisfied with the extra cost.

Visit: If the service users are satisfied with the reduced time and even with extra cost, they will frequently use the flyover than the traditional surface road.

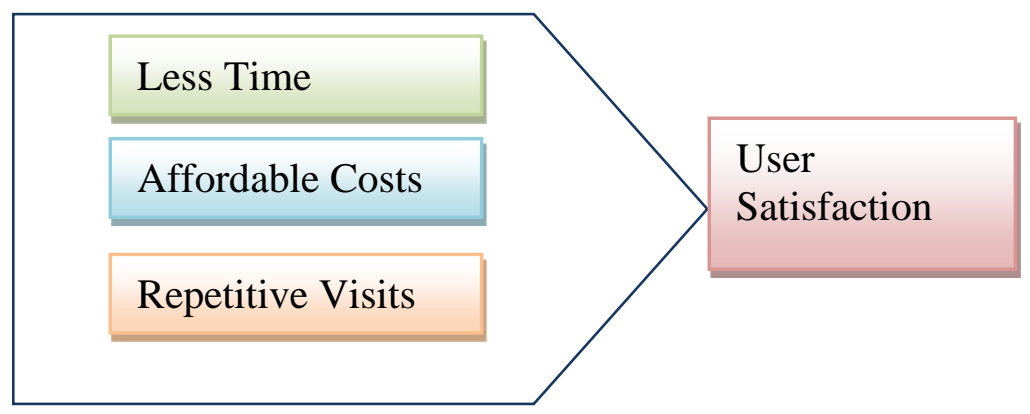

Figure 1: Analytical Framework of the Study

Here it is to be noted that the service users of the MMHF remain satisfied as long as less time is needed to pass this distance than the surface road, the amount of toll taken to use the flyover is affordable and thus their satisfactions are reflected through repetitive use of flyover.

\section{Findings of the Study}

Receiving government services with service cost

Development through infrastructural expansion has been deemed one of the top primacies of the economic advancement of a country because it facilitates communication and thus attracts foreign direct investment. Bangladesh used to face scarcity of own resources to meet up the huge demands of infrastructural advancement in form of developing long connecting highways, constructing flyover, metro rail, etc. to reduce traffic congestion at the city level. To facilitate infrastructural development government needed to encourage alternative sources of investment and thus formulated congenial policies to attract private sector investment in country's development roadmap. After a competitive bidding Orion Group was awarded the job and they came up with the required financial investment and implementation plan and package.

Better service delivery can never be rendered for free of cost; moreover, a partnership with private sector would always increase the price of the service or goods offered for the citizen. As we know the objectives of the public agencies 
and private business organizations are different, rather opposite where government does eye on providing voluntary services, private on the other, works for its financial gain. Under this assumption and factual reality Orion Group was awarded the concession to design, construct, maintain and operate this project resting assured that this kind of project will not only promote their reputation but also help recover investment with significant profit margin through imposing Toll from the vehicle that would use the flyover. Historically in Bangladesh using public roads and highways has been free of cost in most cases (except bridges) and service users are not used to pay for using roads and highways. Rendering services, especially road and highways with service cost has been a paradigm shift for the service users.

\section{Rate of Tolls for rendering services}

As mentioned earlier that the MMH Flyover users have to pay toll for using the service, it is important to know the amount or rates of toll that have been imposed and collected from the vehicle and subsequently collect information regarding whether the service users are satisfied with the service price. The rates of toll have been shown through table 2 .

Table 2: Amount of Toll paid by different categories of vehicle

\begin{tabular}{|l|c|}
\hline Vehicles & Toll in BDT \\
\hline Motorcycle (two wheelers) & 10 \\
\hline CNG and Auto (three wheelers) & 18 \\
\hline Car & 60 \\
\hline Jeep & 70 \\
\hline Microbus & 85 \\
\hline Pickup & 130 \\
\hline Minibus & 173 \\
\hline Bus & 260 \\
\hline Truck/ Four wheelers & 173 \\
\hline Truck/ Six wheelers & 260 \\
\hline Trailer & 375 \\
\hline
\end{tabular}

Source: From Toll collection booth of MMHF

\section{User Satisfaction on the use of Flyover}


The study team conducted a small-scale survey to assess whether the service users are satisfied with the service received using the MMH Flyover. The service impact has been categorized into three relevant variables; time, cost, and visit. The respondents have been asked questions on whether they are satisfied with the time needed to pass through the flyover to their destination, whether they are comfortable or happy with the amount of toll to be paid for the use of flyover and whether they use this flyover quite frequently if and when required to pass through this route. It is quite evident that the service users in a significant number are satisfied with each category of investigation. 94\% of the service users are satisfied with the time needed to pass through the flyover, where similarly around $91 \%$ of them said that they would visit or use this flyover if and when required. The satisfaction level of the service users in case of cost of services is around $64 \%$ which is relatively lower than the other indicators but still around two third of the studied service users are quite happy with the price of service. The level of satisfaction under each of these three variables has been shown by the figure 2 .

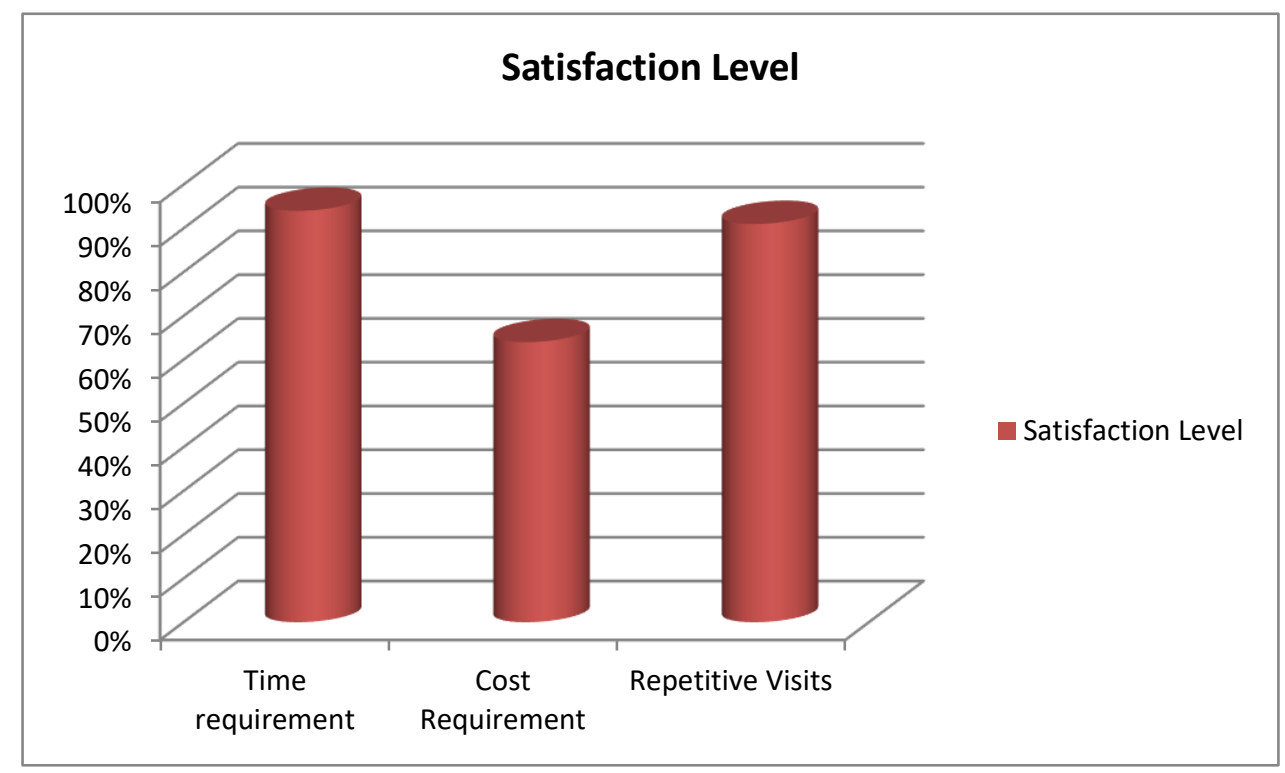

Figure 2: Level of Satisfaction of the Service Users

\section{Positive Impacts on Service Users and Providers}

Reduced Time: In a city with devastating traffic congestion flyover of $11 \mathrm{~km}$ is quite a long distance that provides relief to the Users to get rid of traffic 
congestion, saving time, fuel consumption, etc. 94 respondents of study which is 94\% of the total respondents has been found very satisfied with the time needed to pass through this $11 \mathrm{~km}$ of distance. Even the respondents said that sometimes they take a long route to avoid the main surface road, and even had to drive backwards to get on to the flyover because once you take the route of the flyover instead of the surface road it would eventually save much of their time. Only two respondents seem to not be satisfied with the time spent on the flyover and they opined that during the peak hours there remains traffic congestion even on the flyover that causes extra time to reach their destination.

Frequent Visits: When flyover users are satisfied with the overall services received using the flyover they tend to use or take the services again and again. It has been found that $91 \%$ of the service users are very satisfied with the service and they frequently use the flyover if they need to pass through that very route. It is interesting to note that even the public buses that take passengers from every stoppage and even from the middle of the road are found using the flyover where there is no opportunity for taking passengers on board from the middle of the road. It may cause reduced income of the bus owners, but the drivers said that now they can easily adjust the income with increased trip to their route. Reduced time needed to reach the destination ultimately helped them go for extra trip. It is also found that the private vehicle also frequently uses this flyover instead of surface road. Some of the respondents, who are not happy with the amount of toll, were also found using the flyover quite frequently.

User satisfaction despite increased cost: Around two third of the respondents, $64 \%$ to be precise opined their satisfaction with the amount of toll to use the flyover and whilst one third of the respondents were found unhappy with the amount of toll. Earlier, we all know that service users did not have to pay a single Paisa (penny) for using the surface road of this route but to some extent now they need to pay a significant amount of money at the toll counter. The respondents who were found satisfied with the amount said that it is better to spend an increased amount of money as toll on the flyover than sitting idle at the traffic congestion for hours.

Hassle free Route: Any research work on traffic congestion and its' causes would depict that there are several problems including faulty design of roads, running of different categories of vehicle on the same lane, frequent crossroads and roundabouts, sudden crossing of human being, unprofessional attitude of the 
Traffic Police, etc. This flyover has managed to reduce or eliminate some of these problems, especially running of slow vehicle like Rickshaw and Bicycle on the flyover and unnecessary intervention of the Traffic Police. Some of the respondents especially drivers of public vehicle and track opined that using flyover helps them avoid encounter and unprofessional attitude of the Traffic Police. The Police are known for asking bribe from the drivers, especially during the off peak and night and avoiding them to some extent help them save some money. Using flyover can facilitate them with this kind of hassle-free smooth travel in this $11 \mathrm{~km}$ of road.

Image building for both Government and Private Sector: There have been several instances of partnerships in the country between government and private sector, donor agencies, especially NGOs for better service delivery but in most cases the service users did not have to pay any money for rendering services. This is in fact the first of a case where mega infrastructural project like MMHF had been built in partnership between government and business sector where Orion Group invested a huge amount to implement the project and was contracted to recover the money with profit by imposing tolls for 24 years. This very principle of the contract would affect the service price and consequently rates of toll have been determined which to some service users are a bit higher than their expectation. Despite this feature, all the service users have been found very happy with this project since it reduces time, encourages frequent use and the cost is affordable to most of the users. It in the long run builds positive images both for the government and the private sectors where people start trusting that the government is trying to provide better services to the people and on the other hand private sector can take part in the nation building process.

\section{Challenges of this Partnership Project}

Tendency of Increased Traffic Congestion on Flyover: Now-a-days it has been observed that there is a tendency of increased traffic congestion on this flyover. Respondents through in-depth interviews analysed the fact that the positive impacts of the use of this Flyover may cause increasing traffic congestion on the flyover. The traffic congestion under the flyover has been deteriorating day by day due to increased number of vehicle and therefore it creates a tendency of the overuse of the flyover. Most of the vehicles passing through that route are found interested to use the flyover than the general road underneath it. It increases the 
number of flyover users in a very significant number and increased number of flyover use creates the tendency of increased traffic congestion.

One Lane and One Toll Counter: Given the width of the flyover in almost all the places there are only two lanes; in-way and out-way. Therefore, in most areas on it, the vehicles are run one after another maintaining a single row and since vehicles are run in a single row there is only one counter to collect toll from the vehicles. Due to inadequate number of toll counter and increased number of vehicles there remains a long queue waiting from the toll counter. It has been observed that during the daytime and evening there is a long queue of vehicles which in consequence increases the time to pass through the flyover. Reduced time being one of the objectives of this partnership is now being hampered heavily due to this nature and overuse of the project.

Extension of Partnership may cause Increased Cost: In-depth interview with the high officials of Orion Group provided the research with another dimension of this project which may increase the service cost in the long run. According to the contract with the government the private implementing agency, Orion Group is supposed to collect toll for 24 years so that they can recover their investment with profit margin stipulated in the project proposal. The officials said the amount of money collected every day from the project may not recover the money in 24 years and the government may need to extend the tenure of the toll collection agreement or otherwise, the amount of toll needs to be increased to recover the money in 24 years. Under the BOOT method of partnership, the implementing agency is supposed to transfer the project or assets to the government after the contract tenure is completed provided private sector earns their profit margin. In case of this confusion of generating desired turnover from the project there is a possibility of extending the management contract. This will, for all intents and purposes, either increase the service price by increasing the amount of toll or service users need to bear this amount of toll even after the completion of 24 years of contract.

Construction of Alternative Transportation may Decrease the use of this Flyover: As we all know, Dhaka is one of the densely populated cities in the world with minimum number of highways that barely ensure inter and intra connection with the city. Inadequate number of roads expedites traffic congestion throughout the city. The present government has taken many decisions to reduce this traffic congestion in the city by implementing Mass Rapid Transit (MRT) including 
metro rail, Bus Rapid Transit (BRT), By-pass roads, waterways, elevated expressways, etc. The implementation of these projects in the recent future would decrease the use of this flyover and this flyover will lose turnover. In that case, the timing of passing through this flyover may decrease but the amount of toll would surely increase since the private sector would get their return with profit. Any increase of the toll price would affect the satisfaction level of the users of this flyover.

\section{Conclusion}

Public administration has been experiencing changes in service delivery for years due to its nature and PPP is one of the most flourishing models in this regard. PPP has become one of the major tools to deliver services to the citizen in different countries around the world. Bangladesh is not an exception and it has set sectoral goals in meeting the standard of good governance to ensure sustainable development. In doing so, Bangladesh is trying to establish collaborative arrangements to implement several development projects throughout the country and through G2G partnerships with the impression of two broad objectives, first one is developing infrastructure and second one is boosting economic growth. Here comes the PPP to facilitate the said collaboration among different parties from public and private sector. PPP requires partnership which reduces pressure on national budget and shares investment risks. As a PPP project, MMHF has a great contribution to the development of the country. Despite having some shortcomings in operation and outcome, it provides very good lesson to the government and investors. There is a clear message of the project that PPP is beneficial for public, but for its sustainability and effectiveness in operation, a strong commitment and more sophisticated feasibility study before launching this kind of project is very crucial. MMHF is a landmark step in developing communication in the country by a joint public-private venture. Other investors can use these projects as a very realistic and successful example in taking any PPP project ahead.

TCV (Time, Cost and Visit) though relatively a new method of satisfaction measurement, has been in use for so many projects in Bangladesh, especially in case of online service delivery. Despite being an offline entity MMHF has been studied through this method and it has been observed that under present research this model can be effectively used for public service delivery and we assume that 
this can also be used for satisfaction measurement for different public and private services especially where people need to go/visit physically, requires time and money. Despite many drawbacks, as suggested by different researchers and newspaper reporters, people using the flyover are still very satisfied with the time required to pass through the flyover to their destination, relatively happy with the amount of money needs to spend while availing the service and therefore, the service users are using this flyover every now and then. The research team suggests that this TCV model can also be used for measuring other services, especially those are provided through citizens' charter at different tiers of local government and field administration.

\section{References}

Access to Information (a2i) Programme. (2015). A TCV Study on Online Admission System of the University of Dhaka. Prime Minister's Office. Government of Bangladesh.

Access to Information (a2i) Programme. (2016). e-Services for all. The Office of the Prime Minister, Government of Bangladesh.

Chakraborty, S. (2016). Traffic Congestion in Dhaka City and its Economic Impact. Dhaka University Journal of Business Studies , 1(1), 45-68.

Government of Bangladesh. GoB, (2010). Policy and Strategy for Public-Private Partnership (PPP)2010, Bangladesh Gazette, Registered No DA-1, Dhaka: Bangladesh Government Press.

Hussain, I., \& May, M. A. (2014). The Access to Information Programme Transforming public service delivery in Bangladesh. (1-11), Dhaka: BRAC.

Islam, M. S., \& Mehjabeen, M. (2011), "Public-Private Partnerships in Bangladesh: Managing Issues under PPPs", Social Science Review, Vol. 28(1), 184.

Korean International Cooperation Agency. (2018). e-Government Master Plan for Digital Bangladesh. Retrieved from: http://bcc.portal.gov.bd/sites/default/files/files/bcc.portal.gov.bd/ page/ecbb5603_1eac_4bf0_99fe_628e9980c279/e-Government\%20Masterplan\%20for\% 20Digital\%20Bangladesh_V6.0\%20(2).pdf (Accessed on August 25, 2020)

Islam, M. R., Anwari, N., Hoque, M. S. (2018): Performance Evaluation of Jatrabari-Gulistan Flyover (Mayor Mohammad Hanif Flyover), $6^{\text {th }}$ International Congress on Technology Engineering and Science, July 19-20, Kuala Lampur, Malaysia.

Organisation for Economic Co-operation and Development (OECD). (2013). Government at a Glance. Paris: OECD Publishing.

Rashid, S., \& Hasan, S. (2018). Connecting State and Citizens: Transformation Through eGovernance in Rural Bangladesh. Dhaka: Access to Information (a2i) Programme, Prime Minister's Office, Government of Bangladesh.

Shumi, F. R., Saha, P., Aziz, A., Elma, A., \& Ara, R. (2015). TCV Analysis of Online Admission: The Case of University of Dhaka. Journal of Business Review-Bangladesh. 4(2), 190-199

Van Ryzin, G. G., Muzzio, D., Immerwahr, S., Gulick, L., \& Martinez, E. (2004). Drivers and consequences of citizen satisfaction: An application of the American customer satisfaction index model to New York City. Public Administration Review, 64(3), 331-341. 